\title{
Influence of welding sequence on welding distortions in pipes
}

\author{
I. Sattari-Far ${ }^{\mathrm{a}, *}$ and Y. Javadi
}

a Assistant professor, Faculty of Mechanical Engineering, Amirkabir University of Technology, Tehran, Iran

b Research student, Faculty of Mechanical Engineering, Amirkabir University of Technology, Tehran, Iran

\begin{abstract}
This paper presents a three dimensional thermo-mechanical analysis to investigate the effect of welding sequence on welding deformations in pipe-pipe joints of AISI stainless steel type. Single-pass TIG welding with V-joint geometry in pipes having a diameter of $274 \mathrm{~mm}$ and a thickness of $6.2 \mathrm{~mm}$ is studied here. Nine different welding sequences are analyzed. The finite element results are compared with experimental data. It has been shown that selecting a suitable welding sequence can substantially decrease the amount of welding distortions in this pipe geometry.
\end{abstract}

Keywords: Finite Element Simulation; Welding Distortion; Welding Sequence; Welding Modelling

\section{Introduction}

Pipe welding is widely used in a variety of engineering applications such as oil and gas industries, nuclear and thermal power plants and chemical plants. A non-uniform temperature field, applied during welding process, produces deformation and residual stresses in welded structures. In the pipe welding, "diameter change" is the most usual deformation type. After welding, pipe diameter is changed from the original diameter because of welding shrinkage, as shown in Fig. 1. The diameter changes are not uniform in the circumferential direction of the pipe, thus the pipe sections would not be circle after the welding process. This non-uniformity of the pipe section is called "ovality", and is shown in Fig. 2.

The extent of deformations and residual stresses in welded components depends on several factors such as geometrical size, welding parameters, welding sequence and applied structural boundary conditions.

Finite element (FE) simulation has become a popular tool for the prediction of welding distortions and residual stresses. A substantial amount of simulation and experimental work focusing on circumferential welding

\footnotetext{
* Corresponding Author. Tel.: +98 21 64543426; Fax : +98 2166419736

E-mail address: sattari@aut.ac.ir (I. Sattari-Far).
}

with emphasis on pipe welding is available in the literature [1-12]. To reduce computational power requirements, assumptions such as rotational symmetry and lateral symmetry have been employed in numerical simulations [4-6]. These assumptions reduce the computational demand but may make the problem over simplified by limiting the analysis to one section of the complete geometry and eliminate modelling of welding sequence. Therefore, these simplified models are not capable of predicting the effects of weld start/stop locations, welding sequence and tack welds.

Fricke et al. [10] investigated multi-pass welding on a complete three-dimensional (3D) model for pipe weld, but nothing is mentioned about welding sequence. Tsai et al. [13] employed a 3D shell element and moving welding arc to simulate welding residual stresses in AISI 304 stainless pipe. Li et al. [14] developed a full 3D FE model to simulate a multi-pass narrow gap girth welding process. 


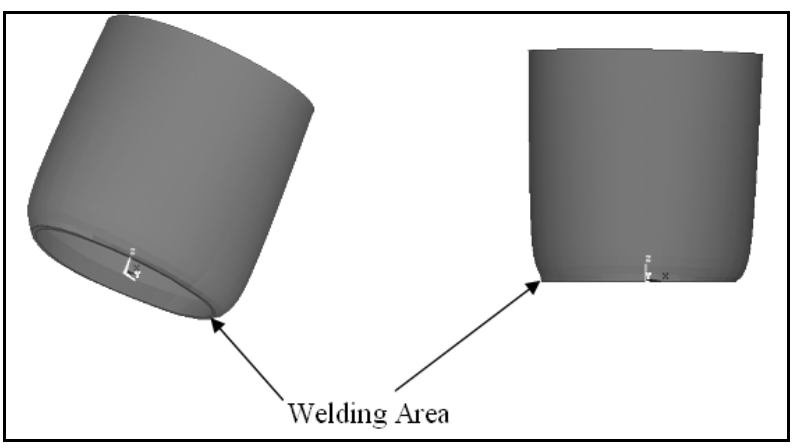

Fig. 1. Pipe diameter variation after welding.

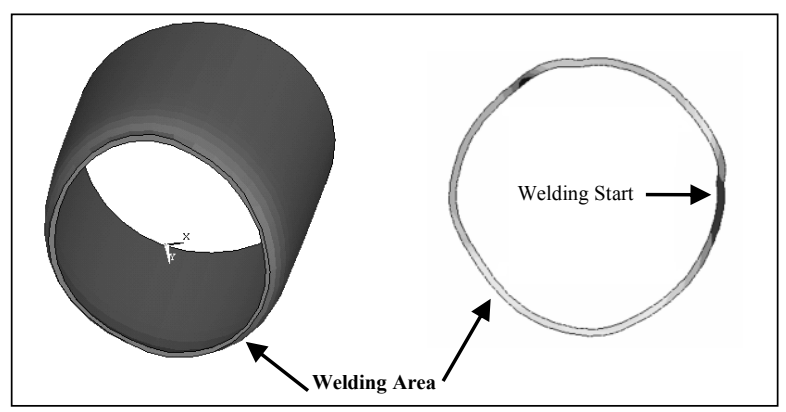

Fig. 2. Ovality after welding.

Recently, Jiang and co-workers [15] used a 3D FE model to predict temperature distributions in a multi-pass welded pipe branch junction. However, none of these works has simulated a fully 3D model for comparing deferent welding sequences in pipe welding.

This paper presents a parametric study to determine the effect of welding sequence on welding distortions. 3D FE simulation of a single pass butt weld joint is performed using the FE code ANSYS [16]. Two stainless steel pipes with an outer diameter of $273.7 \mathrm{~mm}$, wall thickness of 6.2 $\mathrm{mm}$ and a length of $300 \mathrm{~mm}$ are welded together in a single-pass V-joint. Welding start locations and tack weld positions are shown in Fig. 3. A total of nine different sequences are analyzed for the welding sequence of this pipe, as shown in Fig. 4. The case entitled as 1-seg, in which the weld is conducted entirely in one segment from the start to the final location, is chosen as the basic case here. This case has four tack welds, and is validated experimentally in this study. Any effects of tack welds on distortions and residual stresses are neglected in the analysis.

\section{Modelling of physical phenomena}

Numerical simulation of residual stresses and distortions due to welding need to accurately take account of the interactions between heat transfer, metallurgical transformations and mechanical fields.
The phenomena involved in the heat input such as arc, material interactions as well as fluid dynamics in the weld pool are not accurately described. From the thermomechanical point of view, the heat input can be seen as a volumetric or surfaced energy distribution, and the fluid flow effect, which leads to homogenize the temperature in the molten area, can be simply taken into account by increasing the thermal conductivity over the fusion temperature.

The different phenomena involved and their couplings are given in Fig. . As no metallurgical transformation occurs in the 304 stainless steel considered in this paper, no detailed modelling of the melting is considered here.

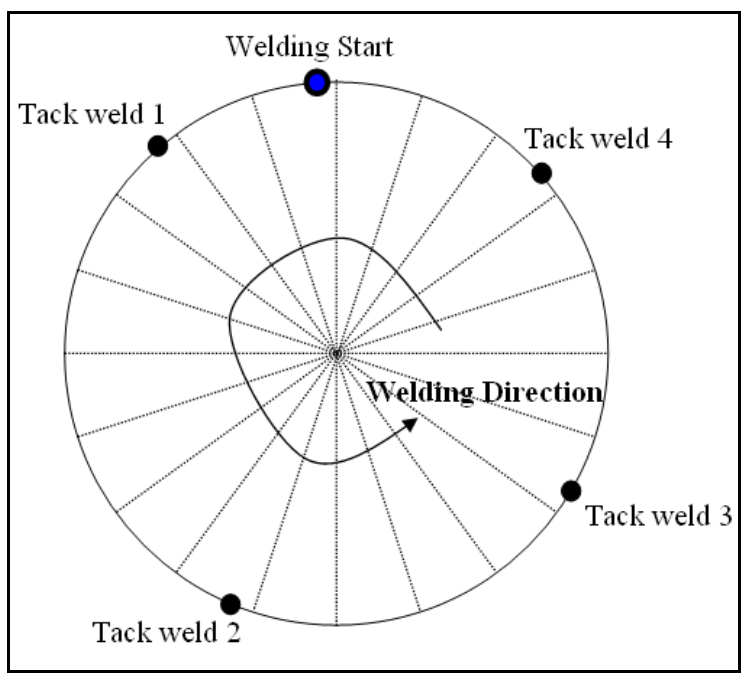

Fig. 3. Welding start and tack welds position.

\subsection{Heat transfer analysis}

The heat transfers in solids are described by the heat equation:

$\rho \frac{d H}{d t}-\operatorname{div}(\lambda \operatorname{grad} T)-Q=0$

$$
\lambda \operatorname{grad} T . n=q(T, t) \quad \text { on } \partial \Omega_{q}
$$

$$
T=T_{p}(t) \quad \text { on } \partial \Omega_{t}
$$

Where $\rho, H, \lambda$ and $T$ are density, enthalpy, thermal conductivity and temperature, respectively. In Eq. (1), $Q$ represents an internal heat source. In Eq. (2), $n$ is the outward normal vector of domain $\delta \Omega$ and $q$ the heat flux density that can depend on temperature and time to model convective heat exchanges on the surface. $T p$ represents a prescribed temperature. The heat input is represented by an internal heat source. 
In the present study, the double ellipsoid heat source configuration proposed by Goldak et al. [17] is used, as shown in Fig. 6. As it is seen, the front half of the heat source is the quadrant of one ellipsoidal source, and the rear half is the quadrant of another ellipsoid. In this model, the fractions of $f_{f}$ and $f_{r}$ of the heat deposited in the front and rear quadrants are needed, where $f_{f}+f_{r}=2$. The power density distribution inside the front quadrant is:

$$
q_{f}(x, y, z)=\frac{6 \sqrt{3} f_{f} Q}{a_{f} b c \pi^{3 / 2}} e^{\left(-3 x^{2} / a_{f}^{2}\right)} e^{\left(-3 y^{2} / b^{2}\right)} e^{\left(-3 z^{2} / c^{2}\right)}
$$

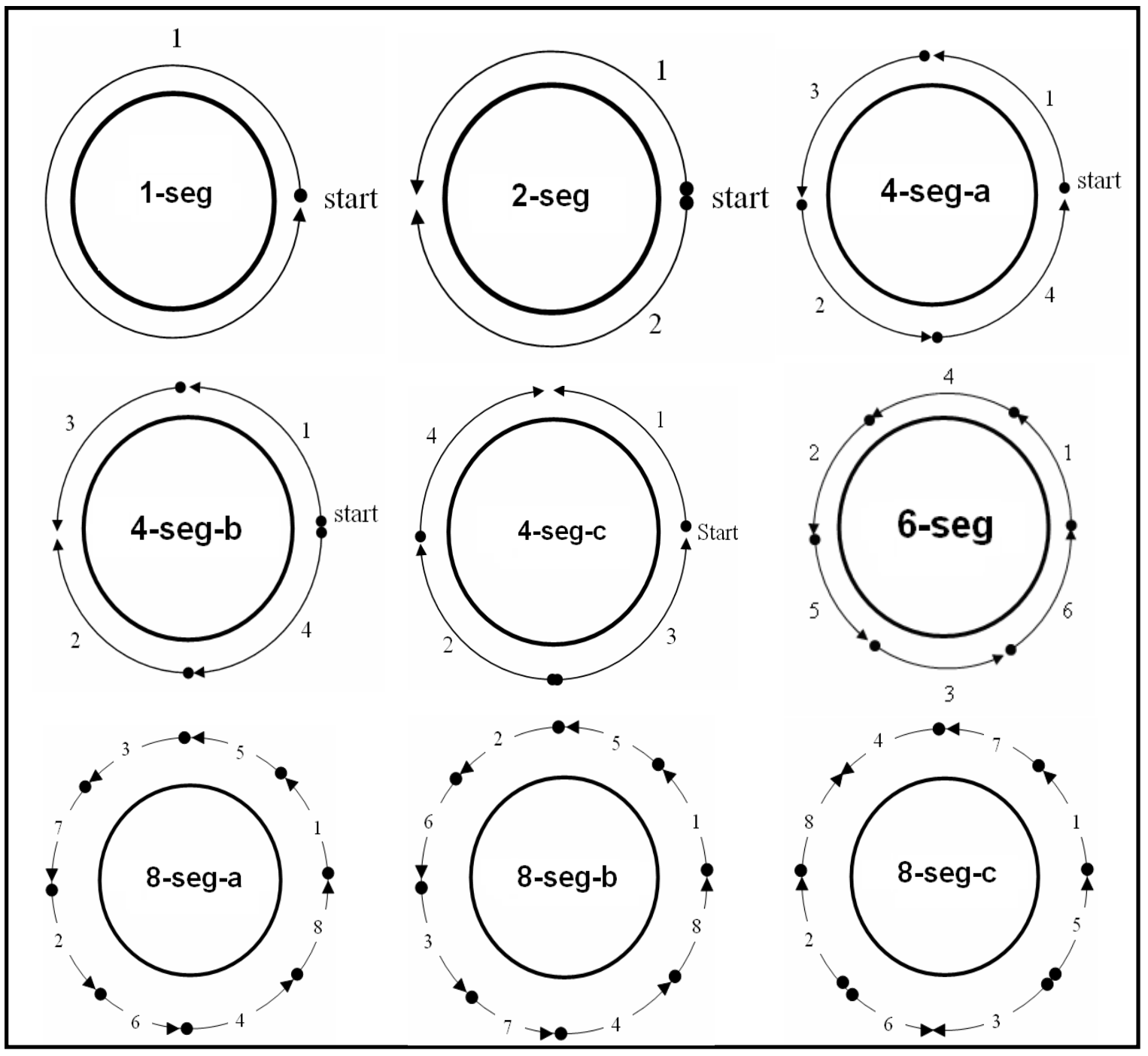

Fig. 4. Nine sequences for pipe welding investigated in this study.

Similarly, for the rear quadrant of the source the power density distribution inside the ellipsoid becomes:

$q_{r}(x, y, z)=\frac{6 \sqrt{3} f_{r} Q}{a_{r} b c \pi^{3 / 2}} e^{\left(-3 x^{2} / a_{r}{ }^{2}\right)} e^{\left(-3 y^{2} / b^{2}\right)} e^{\left(-3 z^{2} / c^{2}\right)}$
Physically these parameters are the radial dimensions of the molten zone in front, behind, to the side, and underneath the arc. If the cross-section of the molten zone is known from the experiment, these data may be used to fix the heat source dimensions. 


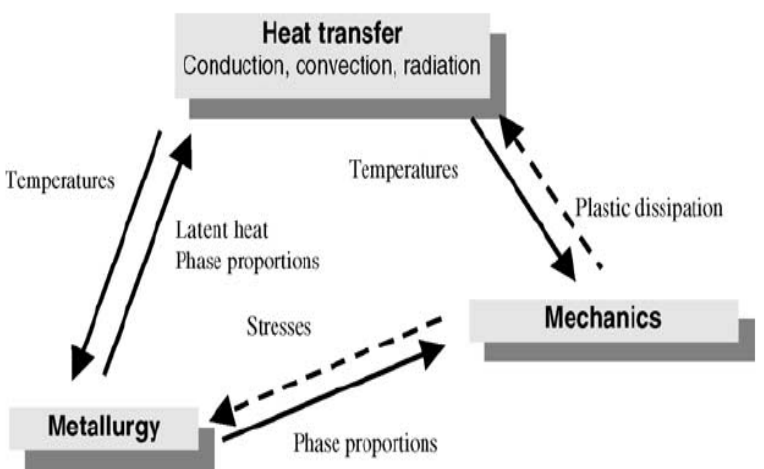

Fig. 5. Physical phenomena involved and their couplings.

If cross-sectional dimensions are not available, the experience data given by Goldak et al. [17] suggest that it is reasonable to take the distance in front of the heat source equal to one-half the weld width and the distance behind the heat source equal to twice the width. These suggestions are used in this paper.

The internal heating due to the plastic dissipation can be neglected considering the small transformation rates generated by a welding operation.

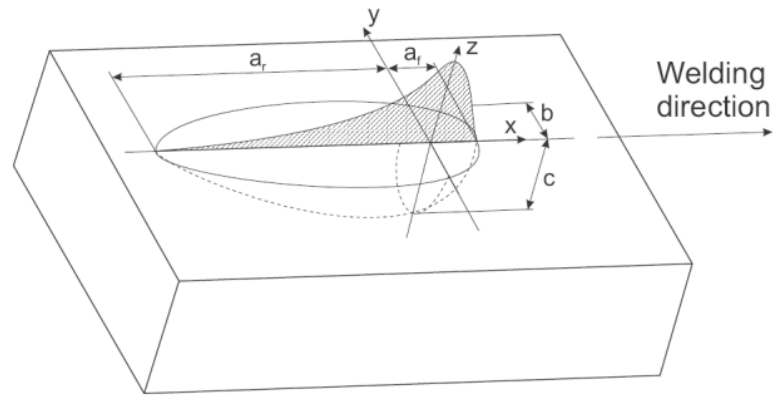

Fig. 6. Double ellipsoid heat source configuration.

\subsection{Mechanical analysis}

The mechanical analysis is based on the usual equations describing the static equilibrium. As the plastic dissipation is neglected in the thermal analysis, thermal and mechanical analyses can be treated separately. Thus, the mechanical calculation is achieved using the temperature fields computed previously by the thermal analysis. The materials are supposed to follow an elastic-plastic behaviour with isotropic hardening. The material parameters Young's modulus, Poisson's ratio, yield stress, strain hardening and heat expansion coefficient are temperature dependent.

\section{Material modelling}

Material modelling has always been a critical issue in the simulation of welding because of the scarcity of material data at elevated temperatures. Some simplifications and approximations are usually introduced to cope with this problem. These simplifications are necessary due to both lack of data and numerical problems when trying to model the actual high-temperature behaviour of the material [18]. The material properties for AISI 304 stainless steel are shown in Fig. . These data are taken from Lindgren [19]. The pipe material and the filler metal are assumed to be of the same chemical compositions.

Due to the lack of data on material properties of the weld metal and heat-affected zone (HAZ), it is assumed in this analysis that thermal and mechanical properties of the weld metal and HAZ are the same as those of the base metal.

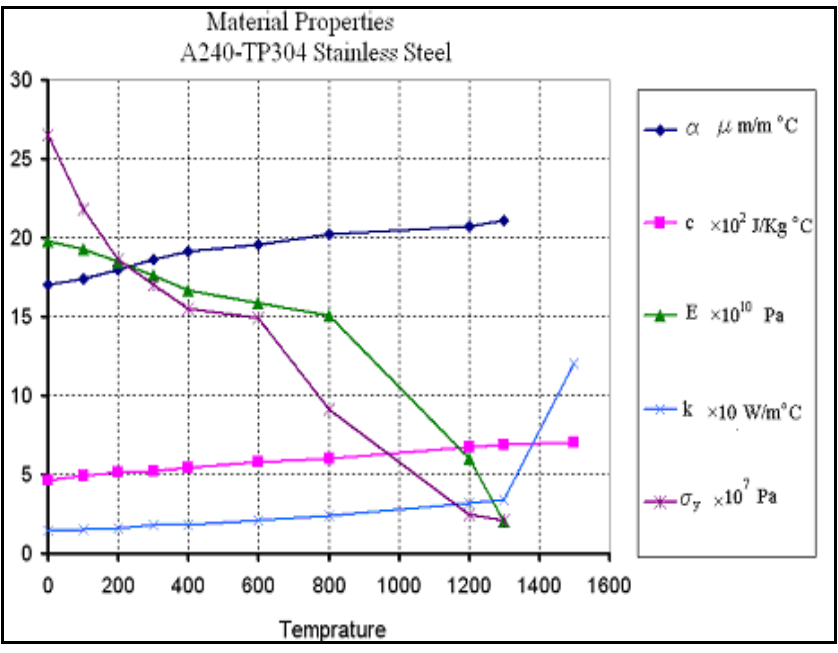

Fig. 7. Material properties for 304 stainless steel used in this study [19].

\section{Finite element modelling}

The problem is formulated as a sequentially coupled thermal stress analysis. First, a non-linear thermal analysis is performed to calculate the temperature history of the whole domain. Then, the results of the thermal analysis are applied as a thermal body load in a non-linear structural analysis to determine distortions. The finite element models for both thermal and structural analysis are the same. The general-purposed FE program ANSYS [16] is used for the analyses. During the analysis a full NewtonRaphson iterative solution technique with direct sparse matrix solver is employed for obtaining a solution. During the thermal analysis, the temperature and the temperature dependent material properties change very rapidly. Thus, a full Newton-Raphson technique with using modified material properties is believed to give more accurate results.

A conventional element technique named 'element birth and death' [20], is used for modelling of the deposited 
weld. A complete FE model is generated in the start of the analysis. However, all elements representing the deposited weld except elements for the tack welds are deactivated by assigning them a very low stiffness. During the thermal analysis, all the nodes of deactivated elements (excluding those shared with the base metal) are also fixed at room temperature till the birth of the respective element. Deactivated elements are reactivated sequentially when they come under the influence of the welding torch. For the subsequent structural analysis, birth of an element takes place at the solidification temperature. Melting and ambient temperatures are set as the reference temperatures (at which thermal strains are zero) for thermal expansion coefficients of the filler and base metals. To avoid excessive distortion, initial strains in the elements are set to zero at the time of element reactivation.

In the thermal analysis, after extinguishing the arc, the FE model was run without any load to return to the ambient temperature of $27^{\circ} \mathrm{C}$. The load steps in the structural analysis are kept the same as in the thermal analysis.

Linear elements are preferred than higher-order elements in non-linear problems of this type [21]. Here, eight-noded-brick elements with linear shape functions are used in the FE modelling. Only one half of the pipes is modelled with assumption of symmetry. The basic FE model, used for all the cases of 9 sequences, is shown in Fig. .

In order to facilitate data mapping between thermal and structural analysis, the same FE model is used with respective element types. For the thermal analysis the element type is SOLID70 which has single degree of freedom, temperature, on its each node. For structural analysis the element type is SOLID45 with three translational degrees of freedom at each node. Due to anticipated high temperature and stress gradients near the weld, a relatively fine mesh is used there. Element sizes increase progressively with distance from the weld centre line.

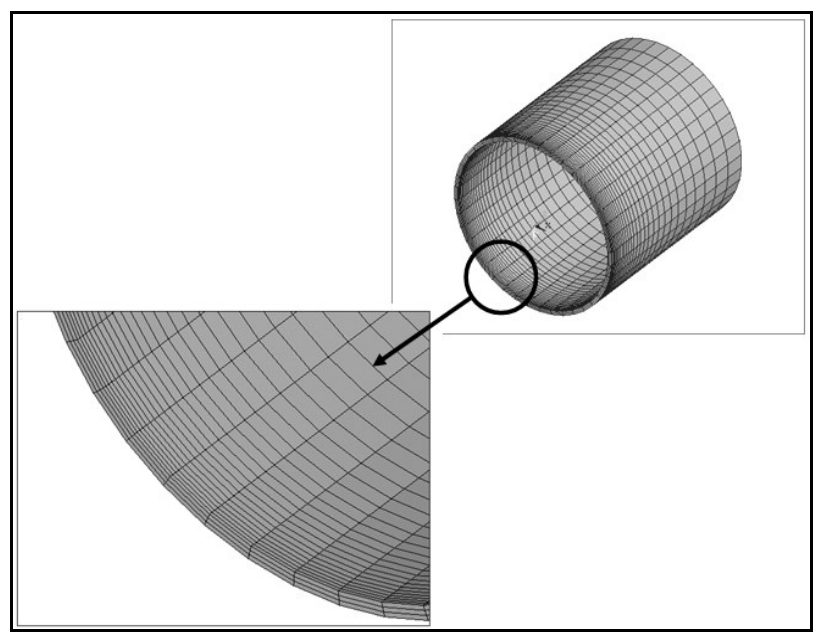

Fig. 8. 3D finite element model.

\section{Experimental studies}

\subsection{Welding}

For circumferential welding of the pipes, an automatic girth welding machine with advanced system control was used. The welding machine was an automatic TIG welding machine with an advanced controller which can simultaneously control Power source, Gripper chuck, Torch driving vehicle, Inert gas supplier and Automatic wire feeder. The automatic circumferential welding system is shown in Fig. .

When the operator push the start button, the controller sends four simultaneous signals to the power source, wire feeder, gripper chuck and inert gas supplier. Consequently, the electrical arc is turned on, the filler is fed into the molten pool, the pipes are rotated with the assigned welding speed, and the inert gas is flowed into the weld pool. In addition, if any oscillatory motion is needed, the controller sends signal to Torch Driving Vehicle.

A single pass butt-weld joint geometry with a single Vgroove $\left(60^{\circ}\right.$ included angle) and without root gap was used, as shown in Fig. 


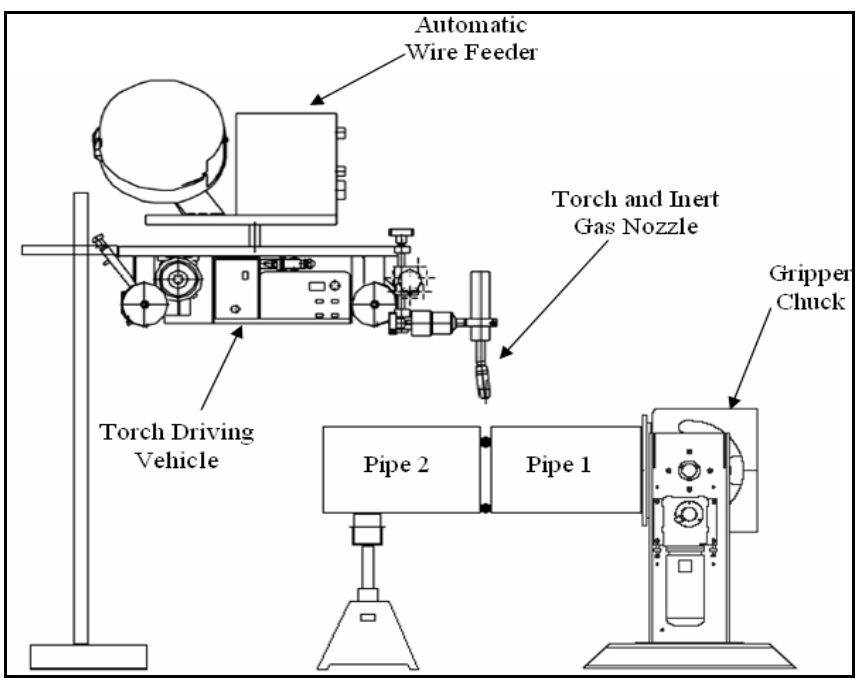

Fig. 9. Automatic circumferential welding system.

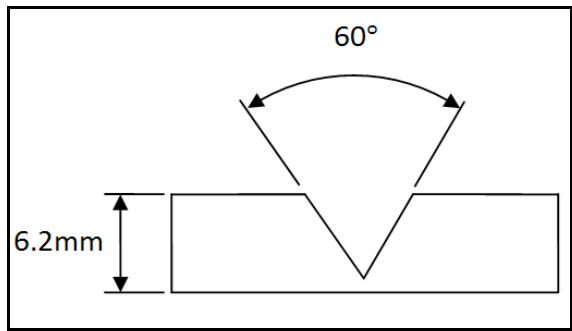

Fig. 10 . Weld groove geometry.

The weld joint contained four initial tack-welds at angular positions of $36^{\circ}, 150^{\circ}, 234^{\circ}$ and $306^{\circ}$ from the weld start position, as shown in Fig. 3. Inert gas was Argon with $99.9999 \%$ purity, the welding current is $230 \mathrm{~A}$, the welding voltage was $20 \mathrm{~V}$, the welding speed was $16 \mathrm{~cm} / \mathrm{min}$ and the wire feeding speed was $90 \mathrm{~cm} / \mathrm{min}$. The welded pipes are shown in Fig. .

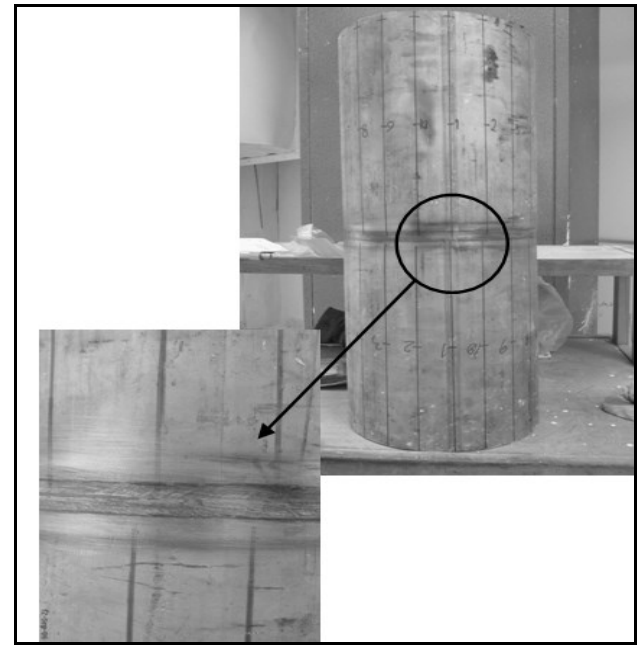

Fig. 11. The welded pipe analyzed in this study.

\subsection{Measurement of the distortions}

The diameters of the pipes were measured before and after welding to determine diameter changes due welding. Measurements were done in 3 sections of any pipe. Fig. 5 shows the measuring sections. This figure shows front view of pipes and the scribed lines in this figure are diametrical measuring locations.

In each section, 10 diameter locations were measured using an accurate micrometer of a range of $250-275 \mathrm{~mm}$ with an accuracy of $0.01 \mathrm{~mm}$.

The measured results before welding showed that the pipe sections were not completely circular. The nominal pipe diameter is $273 \mathrm{~mm}$. After measurement of the pipe diameter at different locations, the average pipe diameter was set to be $273.7 \mathrm{~mm}$ in this analysis. The measurement of the thickness at different locations of the two pipes showed that the thickness of the pipes varied between 6.07 $\mathrm{mm}$ to $6.32 \mathrm{~mm}$. Here, an average value of $6.2 \mathrm{~mm}$ was assigned in the analysis.

The measurements of the diameters at the same locations were repeated after the welding. The differences in the measured results are considered as the diameter changes due to welding. These results are compared with the results from the FE analysis.

\section{Results and Discussion}

\subsection{Verification of the FE modelling}

The FE model was run for 1-seg sequence, and its diameter changes were calculated for the 3 measuring sections shown in Fig. 5. The FE results are compared with the experimental measurements in Fig. 6, Fig. 7 and Fig. 8.

Because of symmetry in welding of the two pipes, any difference between pipe-1 and pipe- 2 measurements is error due to experimental measurements.

Fig. 6 shows the comparison results in section- 1 which is the nearest section to the welding area. It shows good agreement between the FE results and the experimental measurements, having a deviation of about $\pm \% 10$.

It should be noted that this type of pipes are produced from rolling of plates. After rolling, the edges of plates are axially welded together to get the final form of the pipes. This axial weld is not considered in the FE analysis due to the lack of welding information. Consequently, more deviations are observed for locations near the axial welds in the two pipes

Fig. 7 and Fig. 8 show good agreement between the FE results and the experimental measurements, except for 
points having deviations in their experimental measurements of pipe-1 and pipe-2.

Based on the results presented in Fig. 6 13-15, it can be concluded that the developed FE modelling is suitable to estimate the distortions in the pipes welded with different sequences.

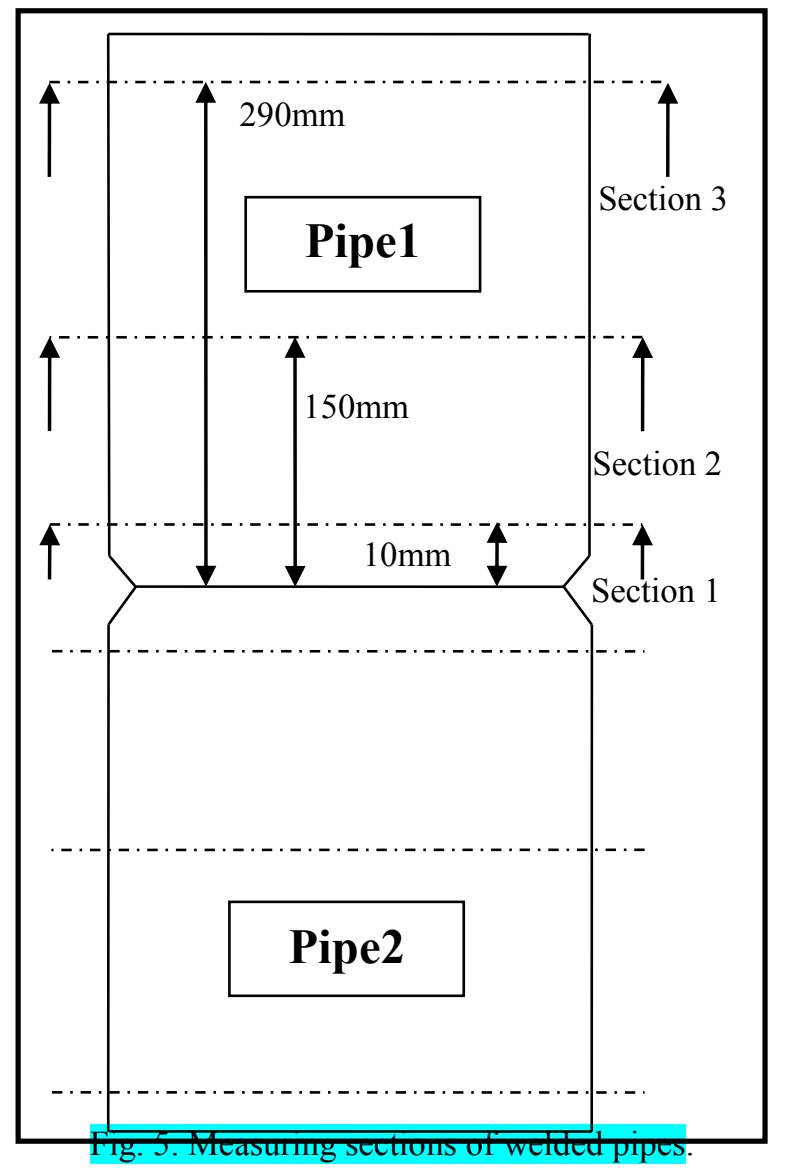




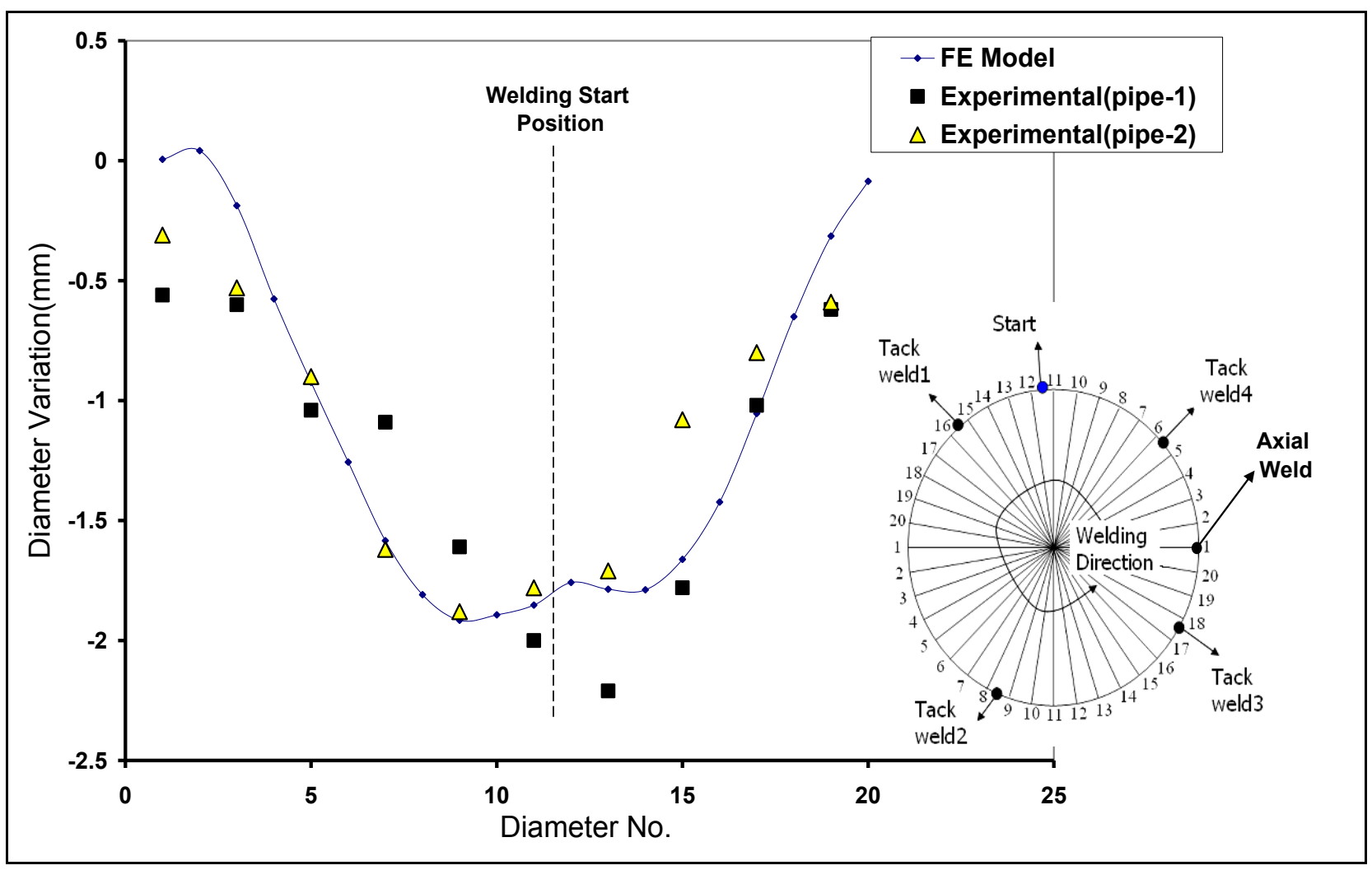

Fig. 6. Comparison of FE model and experimental in section-1.

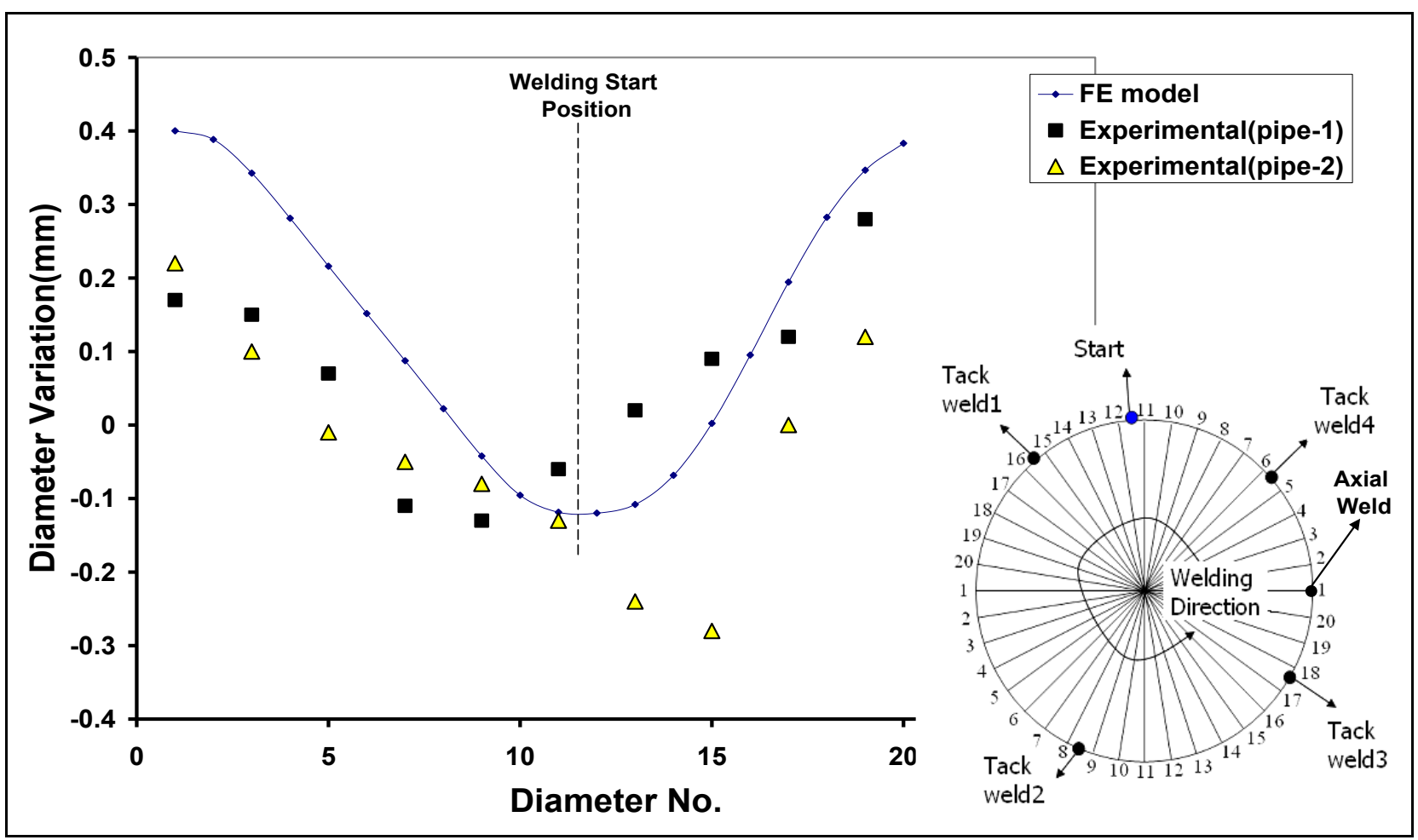

Fig. 7. Comparison of FE model and experimental in section-2. 


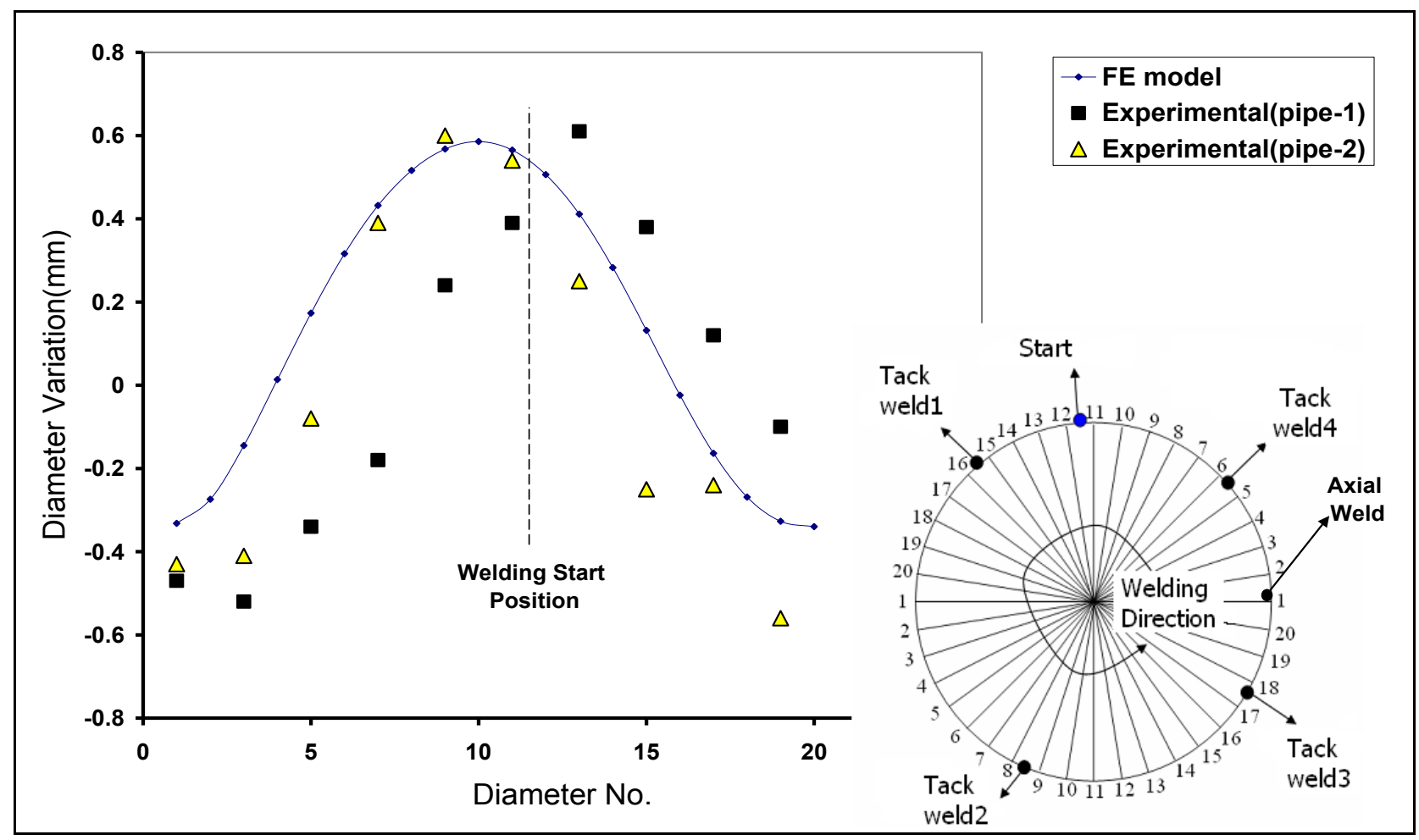

Fig. 8. Comparison of FE model and experimental in section-3.

\subsection{Finding the best sequence}

The FE model is used for the analysis of all nine sequences shown in Fig. 4. Fig. 9 shows comparison of the calculated diameter changes in all nine cases.

For giving a practical use of the results, we consider the following two criteria:

(1) Maximum of Diameter Variations

(2) Average of Diameter Variations.
The Maximum of Diameter Variations means the highest diameter variation in a selected section. This gives a value of the ovality of the pipe due to the welding. For section-1, all diameter variations were decreasing (see Fig. 6 and Fig. 9). For section-2 and section-3, the diameter variations were both decreasing and increasing (see Fig. 7 and Fig. 8). Average of the Diameter Variations indicates an average of all diameter variations in each section. Fig. 12 compare these two criteria in all nine sequences analysed by the FE modelling. 


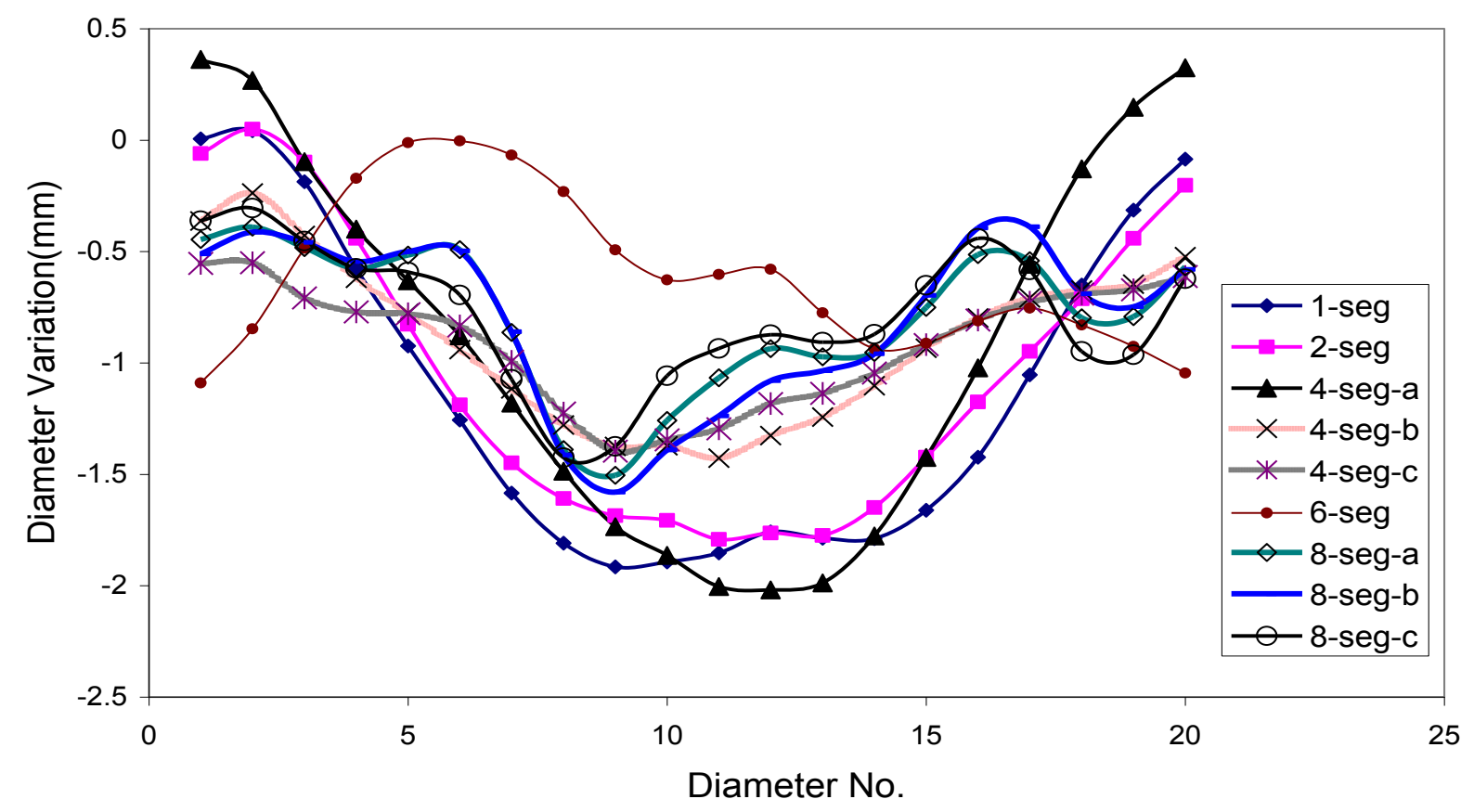

Fig. 9. Comparison between 9 sequences in section-1.

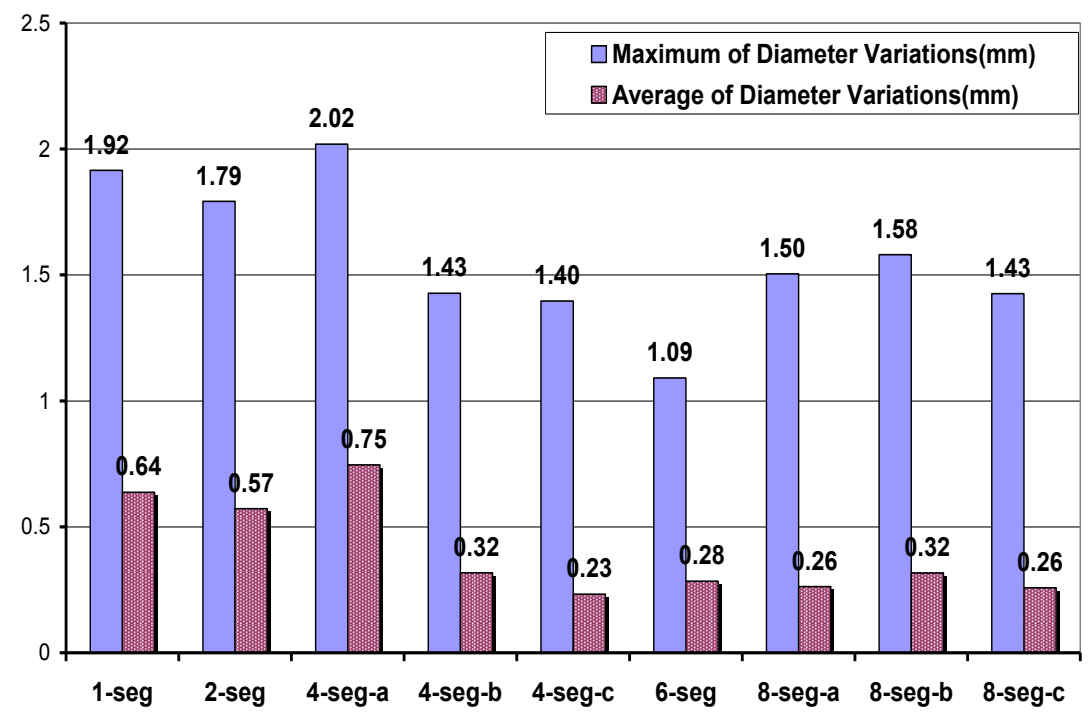

Fig. 10. Comparison between 9 sequences in section-1. 


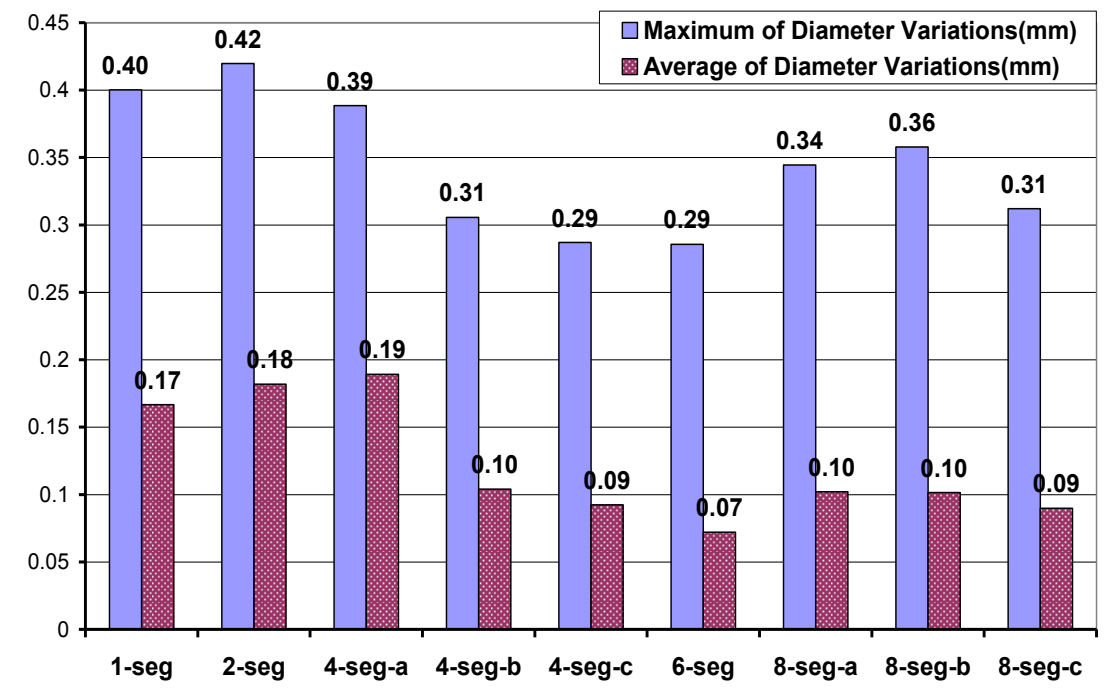

Fig. 11. Comparison between 9 sequences in section-2.

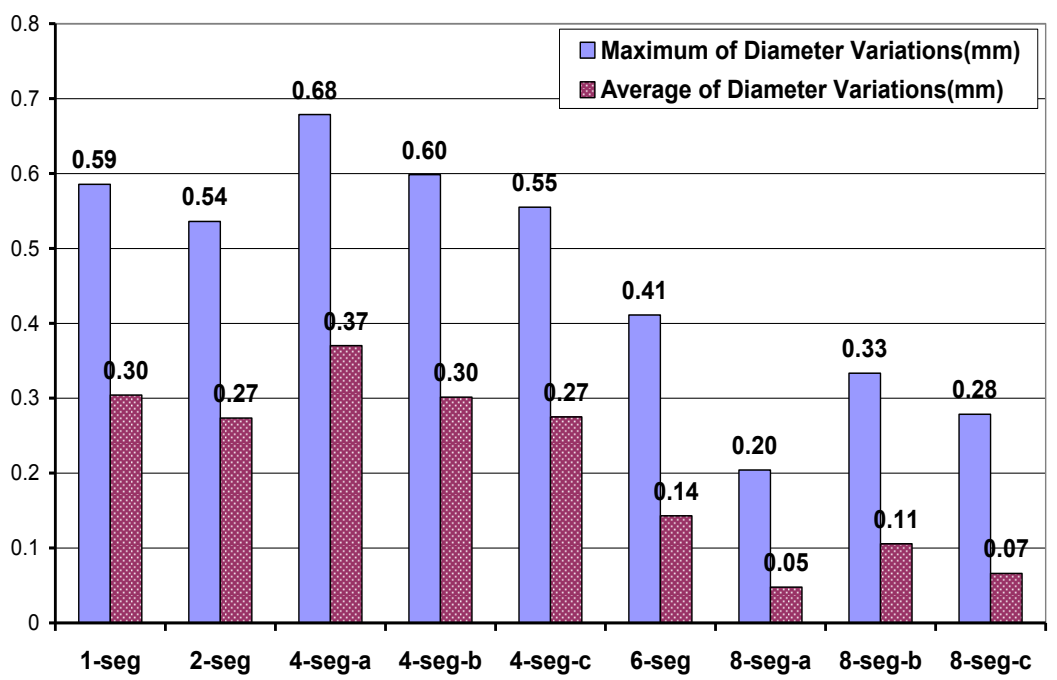

Fig. 12. Comparison between 9 sequences in section-3.

For choosing the best sequence, we should first determine which criterion is of the most interest. For example if the maximum diameter variations in section-3 (farthest locations from the welding area) is critical in a structure, the best choice for welding sequence is 8 -seg-a, (see Fig. 12). In another case if the average of diameter variations in section-2 (mid position of pipe) is important, the welding with 6-segments is the best choice.
Table 1 gives a guideline in choosing the best welding sequence. Here, a value between 1 (poor) to 4 (best) is assigned for any welding sequence based on the specified criteria. For example if maximum diameter variation in section-1 is critical, welding with 6-segments or 4segments-c are the best, and welding with 4-segments-a or 1 -segment are the worst choice for welding sequence. 
Table 1: A guideline in choosing the best welding sequence

Selecting Criteria

Welding Sequence

\begin{tabular}{ccccccccccc}
\cline { 2 - 8 } & 1-seg & 2-seg & 4-seg-a & 4-seg-b & 4-seg-c & 6-seg & 8-seg-a & 8-seg-b & 8-seg-c \\
\hline Max. Diameter Variation in section1 & 1 & 2 & 1 & 3 & 4 & 4 & 2 & 2 & 3 \\
Ave. Diameter Variation in section1 & 1 & 2 & 1 & 2 & 4 & 3 & 3 & 2 & 4 \\
Max. Diameter Variation in section2 & 1 & 1 & 2 & 3 & 4 & 4 & 2 & 2 & 3 \\
Ave. Diameter Variation in section2 & 2 & 1 & 1 & 2 & 3 & 4 & 2 & 3 & 4 \\
Max. Diameter Variation in section3 & 2 & 2 & 1 & 1 & 2 & 3 & 4 & 3 & 4 \\
Ave. Diameter Variation in section3 & 1 & 2 & 1 & 2 & 2 & 3 & 4 & 3 & 4 \\
\hline Average & 1.33 & 1.67 & 1.17 & 2.17 & 3.17 & 3.50 & 2.83 & 2.50 & 3.67 \\
\hline
\end{tabular}

From Table 1, it can be concluded that welding according to 4-seg-c, 6-seg and 8-seg-c are very good welding consequences to minimize welding distortions. The worse case in this study is 4-seg-a. This finding puts question to the common understanding that increasing the number of sequences in welding of pipes always leads to decreasing welding distortions. Here, for instance welding according to 4-seg-a causes more distortion than welding according to 1seg and 2 -seg.

\section{Conclusions}

Based on the FE analysis of AISI 304 stainless steel pipes welded with different welding sequences in the circumferential direction, the following conclusions may be made:

1) Predicted diametric distortions from three dimensional FE analysis are in reasonable agreement with experimental measurements.

2) Welding causes diameter variations (ovality) in the pipes depending on the welded sequence.

\section{References}

[1] Abid M, Nash DH. Risk Assessment studies for Gasketed and Non-gasketed Bolted Pipe Joints, International Pipeline Conference (IPC2002), Calgary Canada, Sep 29 w Oct 3 2002. Proceedings of IPC2002/IPC-27386 2002; 1-11.

[2] Nash DH, Abid M. Surface sensitivity study of non-gasketed flange joint. J Process Mech Eng; Part-E 2004;E4:218.
3) Pipe diameter variations in the welded section are negative (diameter decreases in this section), but with increasing distance from the welding centre line, these variations go to zero and afterward become positive (diameter increase in the sections which are far from welding section).

4) The common understanding that increasing number of welding sequence always leads to decreasing in welding distortions of pipes may be questionable. Here, it is shown that, under certain conditions, welding with four segments may cause more distortions than welding with one or segments.

5) The maximum diameter variation in a section far from the welding area welded with one segment was 0.59 $\mathrm{mm}$. This value could be decreased to $0.2 \mathrm{~mm}$ by using a sequence of 8 segments, indicating the benefits of welding sequence to substantially decrease the welding distortions.

[3] Brickstad B, Josefson BL. A parametric Study of Residual Stresses in Multi-pass Butt-Welded stainless steel pipes. Int J Pres Vessels Piping 1998;75:11-25.

[4] Rybicki EF, Schmueser DW, Stonesifer RW, Groom JJ, Mishaler HW. A Finite Element Model for Residual Stresses and Deflections in Girth-Butt Welded Pipes. Trans ASME J Press Vessel Technol 1978;100:256-62.

[5] Rybicki EF, McGuire PA, Merrick E, Wert J. The Effect of Pipe Thickness on Residual Stresses due to Girth Welds. ASME J Press Vessel Technol 1982;104:204-9. 
[6] Rybicki EF, Stonesifer RB. Computation of residual stresses due to multipass welds in piping system. Trans ASME J Press Vessel Technol 1979;101:149-54.

[7] Karlsson L, Jonsson M, Lindgren LE, Nasstrom M, Troive L. Residual stresses and deformations in a welded thin-walled pipe. In: Rybicki E, Shiratori E, Widera GEO, Miyoshi T, editors. ASME pressure wessels and piping conference 1989. Weld residual stresses and plastic deformation, PVP-vol. 173. Hawai: Honolulu; 1989. p. 7-14.

[8] Dong Y, Hong J, Tasi C, Dong P. Finite element modeling of residual stresses in Austenitic stainless steel pipe girth welds. AWS Weld J, Weld Res Suppl 1997;442:449-444.

[9] Karlsson RI, Josefson BL. Three dimensional finite element analysis of temperature and stresses in single-pass buttwelded pipe. Trans ASME J Press Vessel Technol 1990;112:76-84.

[10] Fricke S, Keim E, Schmidt J. Numerical weld modeling-a method for calculating weld-induced residual stresses. Nucl Eng Des 2001;206: 139-50.

[11] Siddique M, Abid M, Junejo HF, Mufti RA. 3-D finite element simulation of welding residual stresses in pipe-flange joints: effect of welding parameters. Mater Sci Forum 2005;490-491:79-84.

[12] Jonsson M, Karlsson L, Lindgren LE. Simulation of tack welding procedures in Butt joint welding of plates. AWS Weld J, Weld Res Suppl 1995;296s-3301.

[13] Tsai CL, Dong Y, Dong P. 77th Annual AWS. Chicago, USA, 21-25 April 1996; p. 51.
[14] Li M, Atteridge DG, Meekisho LL, West SL. Trends in Welding Research, 4th International Conference, Gaylingurg, Tennessee,USA, 5-8 June 1995; 51-56.

[15] Jiang W, Yahiaoui K, Hall FR. Finite Element Predictions of Temperature Distributions in a Multipass Welded Piping Branch Junction. Trans ASME J Press Vessel Technol 2005; 127(1):7-12.

[16] ANSYS User's Manual, ANSYS User's Manual, SAS IP inc., 1998.

[17] Goldak J, Chakravarti A, Bibby M. A new finite element model for welding heat sources. Metall Trans B 1984;15B: 299-305.

[18] Lindgren LE. Finite element modeling and simulation of welding part 2: improved material modeling. J Thermal Stress 2001;24:195-231.

[19] Lindgren LE, Hedblom R. Modelling of addition of filler material in large deformation analysis of multipass welding. Commun Numer Methods Eng 2001;17:647-57.

[20] Lindgren LE. Finite Element Modeling and Simulation of Welding Part 1: Increased complexity. J Thermal Stress 2001;24: 141-92.

[21] Deng D, Murakawa H. Numerical simulation of temperature field and residual stress in multi-pass welds in stainless steel pipe and comparison with experimental measurements. Computational Materials Science 2006; 37(3): 269-277. 